\title{
Comunicação
}

\section{Aplicação clínica de filtros leucocitários}

\author{
J.O. BORDIN, *A. FABRON J R.
}

Disciplina de Hematologia e Hemoterapia, Universidade Federal de São Paulo - Escola Paulista de Medicina, São Paulo, SP; *Disciplina de Hematologia da Faculdade de Medicina de Marília, Marília, SP.

\begin{abstract}
RESUMO - A presença de leucócitos nos produtos hemoterápicos alogênicos transfundidos tem sido associada à ocorrência de determinadas reações transfusionais, tais como a reação transfusional febril não-hemolítica, a aloimunização e refratariedade à transfusão de plaquetas, a doença enxerto-versus-hospedeiro, e a efeitos imunomodulatórios. Além disso, os leucócitos podem ser vetores de transmissão de agentes infecciosos, tais como o CMV, O HTLV-I/II e o EBV. Tem sido postulado que a remoção dos leucócitos em hemocomponentes mediante uso de filtros leucocitários pode prevenir a ocorrência dessas reações. Entretanto, a eficácia clínica da desleucotização permanece sem definição. Tem sido sugerido que a remoção de $1 \log _{10}$ de leucócitos previne a reação transfusional não-hemolítica, a remoção de $2 \log _{10}$ pode prevenir a transmissão de viroses,
\end{abstract}

A ocorrência e os mecanismos fisiopatológicos de certas reações biológi cas observadas em paci entes submetidos à transfusão sanguínea têm sido associados à presença de leucócitos nos hemocomponentes alogênicos transfundidos ${ }^{1,2}$. Diante disso, alguns investigadores sugerem que, previamente à transfusão, todas as unidades de hemácias ou plaquetas alogênicas devem ser filtradas com filtros leucocitários, uma vez que o processo de filtração parece não modificar a qualidade funcional dos componentes sanguíneos submetidos à filtração e que, possivelmente, a remoção dos leucócitos (desleucotização) pode prevenir a ocorrência de certas reações transfusionais.

U ma unidade de sangue total contém cerca de 2 a $3 \times 10^{9}$ leucócitos. Entre as diferentes técnicas de desleucotização (sedimentação, centrifugação, lavagem, congel amento e descongel amento, e filtração) a filtração é a mais eficiente, uma vez que os filtros de terceira geração, recentemente disponíveis, denominados filtros leucocitários, proporcionam a remoção de mais de $99,9 \%\left(>3 \log _{10}\right)$ dos leucócitos inicialmente presentes no sangue doado, resultando na obtenção de hemocomponentes com menos de $3 \times 10^{6}$ leucócitos al ogênicos residuais (tabela 1) ${ }^{3}$. Entretanto, não estão ainda total mente elucidados quais são os mecanismos pelo enquanto que a remoção de $\geq 3 \log _{10}$ pode ser necessária para a prevenção de aloimunização plaquetária. Entretanto, devido à carência de estudos que analisem apropriadamente as vantagens do uso clínico rotineiro dos filtros, permanecem sem completa definição quais são as reais indicações clínicas para o uso de hemocomponentes desleucotizados; quais são os graus de desleucotização necessários para prevenir as diferentes reações; e se a remoção dos leucócitos deve ser realizada antes ou após o armazenamento do hemocomponente. Dessa maneira, somente estudos clínicos prospectivos poderão definir o custo-benefício da aplicação clínica de filtros leucocitários em hemoterapia.

UNITERMOS: Hemoterapia. Reações transfusionais. Leucócitos. Filtros leucocitários.

quais os leucócitos são retidos no processo de filtração. Tem sido sugerido que os leucócitos são removidos por meio de mecanismo físico (barreira de retenção, fenômeno de superfície, densidade de cargas) e/ou biológico (adesão celular direta, interação célula-célula) ${ }^{4}$. Além disso, a eficiência da desleucotização pelos diferentes tipos de filtros é variável e dependente de várias condições, incluindo a composição da fração celular e do conteúdo plasmático do hemocomponente; a temperatura, o tempo e tipo de armazenamento do hemocomponente; e a velocidade da filtração ${ }^{3,4}$. As células mononucleares capturadas por mecanismo físico, nos poros pequenos em toda a extensão das fibras, não são ativadas, e $60 \%$ a $90 \%$ delas podem ser removidas mediante lavagem do filtro. A captura dos granulócitos, que parece ocorrer por mecanismo biológico por meio da adesão direta à fibra ou por adesão indireta às plaquetas previamente aderidas, é, geralmente, irreversível, e apenas cerca de $30 \%$ a $50 \%$ dessas células podem ser removidas posteriormente por lavagem ${ }^{3,4}$.

O maior obstáculo ao uso rotineiro de filtros leucocitários é o custo, além da incerteza quanto aos reais benefíci os clíni cos dessa medida. Devido à carência de estudos que analisem apropriadamente as vantagens do uso rotineiro de filtros 


\begin{tabular}{|c|c|c|c|}
\hline Filtro & Procedência & Material & Desleucotização (\%) \\
\hline Imugard IG500 & Terumo, Japão & Lã de algodão & $93-98$ \\
\hline Cellselect & BPBI, Holanda & Acetato de celulose & $>99$ \\
\hline Erypur & Organon, Holanda & Acetato de celulose & $96-98$ \\
\hline Miropore & Miiramed, Itália & Acetato de celulose & $95-99$ \\
\hline Leukoseize & Dideco, Itália & Acetato de celulose & $>95$ \\
\hline Sepacell R500 & Asahi, Japão & Poliéster & $95-98$ \\
\hline Optima & NPBI, Holanda & Poliéster & $95-99$ \\
\hline RC100 & Pall, EUA & Poliéster & $98-99$ \\
\hline Leukostop & Miramed, Itália & Poliéster & $95-98$ \\
\hline Leukopak & Travenol, UK & Náilon & $42-54$ \\
\hline Ultipor SQ40S & Pall, EUA & Poliéster & $13-57$ \\
\hline $4 C-2423$ & Fenwall, EUA & Lã de poliéster & 44 \\
\hline
\end{tabular}

Tabela 2 - Efeitos biológicos associados à transfusão de leucócitos alogênicos

1. Reação transfusional febril não-hemolítica

2. Aloimunização e refratariedade à transfusão de plaquetas

3. Doença enxerto-versus-hospedeiro

4. Transmissão de agentes infecciosos

5. Efeitos imunomodulatórios

leucocitários, permanecem, ainda, sem resposta as seguintes questões: 1) quais são as reais indicações clínicas para o uso de hemocomponentes desleucotizados?; 2) quais são os graus de desleucotização necessários para prevenir as diferentes reações bi ológi cas observadas com o uso de hemocomponentes alogênicos?; e 3) quando indicada, a remoção dos leucócitos alogênicos deve ser realizada antes ou após o armazenamento dos hemocomponentes?

De acordo com a literatura atual, o uso de filtros leucocitários pode ser indicado para prevenir as reações biológicas descritas na tabela $2^{1,2}$. Entretanto, deve ser enfatizado que o benefício da desleucotização não está definitivamente comprovado na maioria das indicações clínicas sugeridas. A remoção de $75 \%$ a $90 \%$ de leucócitos parece reduzir significativamente a freqüência da reação transfusional febril não-hemolítica causada por transfusão de hemácias alogênicas em pacientes transfundidos repetidamente; entretanto, o uso de filtros leucocitários não tem si do totalmente eficaz em prevenir essas reações causadas por transfusão de plaquetas alogênicas ${ }^{5,6}$. Por outro lado, a freqüência de aloimunização plaquetária, observada em pacientes transfundidos com concentrados de plaquetas alogênicas não desleucotizados, parece ser consideravel mente maior que a descrita em pacientes transfundidos com concentrados de plaquetas alogênicas desleucotizados ${ }^{1,6}$.
Estudos in vitro sugerem que a redução do número de linfóci tos mediante uso de filtros leucocitários pode diminuir o risco de doença enxertoversus-hospedeiro associada à transfusão de hemocomponentes alogênicos, embora essa complicação transfusional já tenha sido descrita em paci ente transfundido exclusivamente com produtos hemoterápicos submetidos à filtração que removeu mais de $99 \%$ dos leucócitos ${ }^{7}$.

O uso de filtros leucocitários pode prevenir a transmi ssão de agentes infecciosos local izados primariamente em leucócitos, incluindo o citomegalovírus (CMV), o vírus Epstein-Barr (EBV) e o vírus de linfócitos humanos T tipo I ell (HTLV-I/II). Além disso, a filtração pode auxiliar a remoção de bactérias e do Trypanosoma cruzi ${ }^{8,9}$.

Os efeitos imunomodulatórios causados por transfusão de sangue al ogênico parece contribuir para uma diminuição na taxa de rejei ção de transplantes renais, no número de crises agudas em pacientes com doença de Crohn e na taxa de abortos em pacientes com abortos espontâneos de repetição ${ }^{1}$. E m contraste, o uso de transfusões de sangue al ogênico, no período perioperatório, tem sido considerado um fator de risco independente para o aumento do risco de infecções bacterianas e da taxa de recidiva de carcinomas do cól on e do reto ${ }^{1}$. A associação entre transfusões de sangue alogênico e crescimento tumoral está bem estabelecida em model os experimentais ${ }^{10}$. Além disso, está demonstrado que a desleucotização do sangue alogêni co previne o crescimento tumoral em modelos que utilizam animais experimentais ${ }^{10}$.

Finalmente, estudos experimentais sugerem que a remoção dos l eucócitos, realizada no período que antecede o armazenamento do sangue (préarmazenamento), é mais eficaz que quando realizada após o armazenamento imediatamente antes da transfusão (pós-armazenamento) ${ }^{10}$. Nesse sen- 
Tabela 3 - Níveis de desleucotização necessários para a prevenção de certos efeitos biológicos associados à transfusão de leucócitos alogênicos
Efeito biológico

Reação transfusional febril

Transmissão de agentes infecciosos

Aloimunização plaquetária Imunomodulação não-hemolítica

\section{Nível de desleucotização}

pelo menos $1 \log _{10}(90 \%)$

$2 \log _{10}(99 \%)$ a $3 \log _{10}(99,9 \%)$ $\geq 3 \log _{10}(99,9 \%)$

? tido, a associação entre níveis aumentados de interleucinas (IL-1 $\beta$, IL- 6, IL-8, e TNF- $\alpha$ ) em concentrados de plaquetas e a ocorrência de reação transfusional febril não-hemolítica sugere que a remoção dos leucócitos pré-armazenamento previne o acúmulo de substâncias solúveis biologicamenteativas que são sintetizadas eliberadas pelos leucócitos durante o armazenamento do sangue ${ }^{11}$. Os prováveis graus de desleucotização necessários para prevenir as diferentes reações biológicas causadas por transfusão de hemocomponentes alogênicos estão relacionados na tabela 3.

Diante do exposto, a indicação de filtros leucocitários pelo médico primariamente responsável pel o pacientee por pessoas ligadas afetivamente ao paciente parece óbvia, especialmente para pacientes submeti dos a transfusões repetidas e, portanto, com maior risco para reações transfusionais. Entretanto, essa indicação não é tão óbvia para os profissionais responsáveis pela distribuição adequada de recursos em saúde. Em 1994, segundo relatório estatístico anual da Coor denação de Sangue e Hemoderivados (COSAH), foram realizadas, somente pela rede pública de serviços hemoterápicos, cerca de 1 milhão de transfusões de hemocomponentes no Brasil. Considerando-seque o preço médio do filtro leucocitário para a transfusão de um concentrado de hemácias éU $\$ 25.00$, e o preço do filtro leucocitário para oito concentrados de plaquetas é US\$45.00, o uso rotineiro de filtros leucocitários poderia acarretar um acréscimo anual superior a US\$30 milhões aos custos da hemoterapia pública nacional. Dessa maneira, embora a indicação de hemocomponentes desleucotizados pareça ser bastante apropriada para determinados pacientes, existe necessidade de que estudos prospectivos bem elaborados avaliem se os benefícios clínicos adquiridos com essa prática hemoterápica compensam o custo el evado do uso rotineiro de fil tros leucoci tári os em hemoterapia ${ }^{12}$. Nesse contexto, um estudo prospectivo randômico, recentemente realizado na Dinamarca, com pa- cientes submetidos a cirurgia eletiva de cólon e reto, demonstrou que o uso de hemocomponentes desleucotizados reduziu significantemente a freqüência de infecções pós-operatórias, o tempo de internação e o custo hospitalar total dos pacientes transfundidos ${ }^{13}$.

E $m$ conclusão, a tendência atual é a de indicarse o uso de filtros leucocitários para prevenção da reação transfusional febril não-hemolítica e da infecção por CMV, considerando-se as outras indicações como ainda especulativas. Ademais, o uso clínico de filtros leucocitários está vinculado a mel hor defi nição de quais são os grupos de pacientes que seriam real mente beneficiados com a utilização de produtos desleucotizados; quais são os níveis de desleucotização necessários para a prevenção das reações transfusionais; e qual o momento mais apropriado para a desleucotização.

\section{SUMMARY}

\section{Clinical indications for using white blood cell filters}

Leukocytes present in allogeneic blood components have been associated with adverse effects to the recipient. These include the development of febrile transfusion reactions, alloimmunization to human leukocyte antigens, graft-versus-host disease, and immunomodulatory effects. In addition, such leukocytes may be the vector of infectious agents such as CMV, HTLV-I/II, and EBV. It has been postulated that the use of white blood cell filters to reduce the leukocyte content in allogeneic blood products may minimize the occurrence of these biological adverse effects associated with leukocytes present in transfused blood products. However, it is still to be determined the clinical effectiveness of leukodepletion. It has been suggested that $1 \log _{10}$ leukocyte reduction prevents febrile non-hemolytic transfusion reactions; that a $2 \log _{10}$ reduction may prevent the transmission of viroses; and that $a \geq 3 \log _{10}$ reduction may be necessary to prevent platelet alloimmunization. However, because there are no data available as guidelines for the use of leukodepleted blood products for most clinical indications, the use of white cell filters should be restricted to selected patients for whom such data exist. Properly designed prospective clinical trials are necessary to provide data to hel $p$ to define the cost-ben fit of the clinical application of leukodepletion. [Rev Ass Med Brasil 1997; 43(3): 205-8.]

KEY WORDS: Blood transfusion. Transfusion reactions. Leukocytes. Leukocyte filters. 


\section{REFERÊNCIAS BIBLIOGRÁFICAS}

1. Bordin J O, Heddle NM, Blajchman MA. Biologic effects of leukocytes present in transfused cellular blood products. Blood 1994; 94: 1.703-21.

2. Lane TA, Anderson KC, Goodnough LT et al. Leukocyte reduction in blood component therapy. Ann Intern Med 1992; 117: 151-62.

3. Bruil A, Beugeling T, Feijen J, Van Aken WG. The mechanisms of leukocyte by filtration. Transfus Med Rev 1995; 9: 145-66.

4. Dzik S. Leukodepletion blood filters: filter design and mechanisms of leukocyteremoval. Transfus Med Rev 1993; 7: 65-77.

5. Heddle NM, Klama L, Singer J et al. Adverse effects to platelets transfusions are primarily caused by the plasma supernatant. N Engl J Med 1994; 331: 625-8.

6. Heddle NM, Blajchman MA. The leukodepletion of cellular blood products in the prevention of HLA alloimmunization in refractoriness to allogeneic platel et transfusions. Blood 1995; 85: 603-5.

7. Akahoshi M, Takanashi M, Masuda $M$ et al . A case of transfusion-associated graft-versus-host disease not prevented by white cell-reduction filters. Transfusion 1992; 32: 169-71.

8. Goldman M, Delage G. The role of leukodepletion in the control of transfusion-transmitted disease. Transfus Med Rev 1995; 9: 9-19.

9. Moraes-Souza H, Bordin J O, Bardossy L, MacPherson DW, Blajchman MA. Prevention of transfusion-associated Chagas' disease: efficacy of white cell-reduction filters in removing Trypanosoma cruzi from infected blood. Transfusion 1995; 35: 723-6.

10. Bordin J O, Bardossy L, Blajchman MA: Growth enhancement of established tumors by allogeneic blood transfusions in experimental animals and its amel ioration by leukodepletion: the importance of the timing of the leukodepletion. Blood 1994; 84: 344-8.

11. Andreu G. Early leukocyte depletion of cellular blood components reduces red blood cell and platel et storagelesion. Semin Hematol 1991; 28: 22-5.

12. Perkins HA. Is white cell reduction cost-effective? Transfusion 1993; 33: 626-7.

13. J ensen LS, Grunnet N, Hanberg-Sørensen F, J ørgensen J . Cost-effectiveness of blood transfusion and white cell reduction in el ective col orectal surgery. Transfusion 1995; 35: 719-22. 